\title{
Residual resource of force resistance to deformation
}

\author{
Vladimir Rimshin ${ }^{1, *}$, Ekaterina Kuzina ${ }^{1}$, and Alexey Neverov ${ }^{1}$ \\ ${ }^{1}$ Research Institute of Building Physics of the Russian Academy of Architecture and Building \\ Sciences (NIISF RAASN), 21, Locomotive passage, Moscow, 127238, Russia
}

\begin{abstract}
The problem of the durability of reinforced concrete structures of urban engineering structures is currently one of the urgent problems in modern construction due to the continuously growing volume of expensive repair and restoration work, facilities reconstruction, a tendency to a general decrease in quality requirements, and the scale of reinforced concrete structures application in difficult climatic conditions. The theoretical foundations of calculating the residual life of the force resistance to transverse bending with the strength of normal sections in the article, algorithms for calculating the residual life of the force resistance and reinforcement of corrosion-damaged reinforced concrete structures are defined. A complex calculation method is considered in this article that allows to quantitatively assessing the state and resources of crack resistance of reinforced concrete structures damaged by corrosion, to calculate the necessary levels of compression and loss of tension, as well as the exposure to preserve crack resistance in time at specific loading levels and intensities of corrosion effects. The developed complex calculation method can be presented as part of the solution to the problem of preventing and eliminating emergency situations. The theoretical basis for calculating the residual resource of strength resistance to transverse bending by the strength of inclined sections are discussed in the article, the calculation algorithms are studied, and examples are given.
\end{abstract}

\section{Introduction}

Reinforced concrete remains the main material for environmental, communications, utilities, special and a number of other structures in the short term. A significant part of them is intended to protect the population, industries, territories from harmful or even extreme technogenic and climatic loads. In addition, reinforced concrete is used as a material for technological equipment and transport and storage structures requiring a high level of security. At the same time, such structures very often experience the effects of aggressive media, and are exposed to corrosion damage. This reduces their fracture toughness, negatively affects their operational suitability and even structural safety [1-5].

The problem of restoring the operational parameters of damaged reinforced concrete structures as a result of natural or man-made accidents and disasters, construction in

\footnotetext{
${ }^{*}$ Corresponding author: loktevdan@yandex.ru
} 
progress, which have been exposed to climatic effects for a long time, has been sharply identified in recent years [1-7]. The reinforced concrete structures operation in aggressive environments, temperature influences, as well as changes in operating technology and an increase in payloads lead to a decrease in the service life of facilities, to an increase in the volume of work to restore and strengthen reinforced concrete structures.

The purpose of the calculation is to determine the cross-sectional dimensions of the element and the cross-sectional area of the stretched working reinforcement, which guarantee the reliable operation of reinforced concrete structures for a given service life of buildings. The direct task is the need to determine the required amount of stretched reinforcement (or section of an element with a given reinforcement) at given loads. The inverse problem is to check the bearing capacity of the element with a known amount of reinforcement in the element. The article discusses the theoretical basis for calculating the residual resource of strength resistance to transverse bending by the strength of inclined sections, the calculation algorithms are studied, and examples are given.

\section{Materials and Methods}

The influence of the external environment on the mechanical properties, and especially on the processes of mechanical destruction of solids of various kinds, is often tried to be reduced to chemical and electrochemical destruction. However, the influence of the external environment is also expressed in a decrease in strength, or a decrease in resistance to deformation, under the influence of adsorption, i.e. absorption of molecules from the environment by solid surfaces that change upon deformation [8].

Predicting the behavior of concrete under operating conditions can be clarified with objective representations of the physical nature of the strength and deformability of concrete, as well as using modern ideas about the mechanism by which various factors influence these properties. All this is necessary to further improve the methods of calculation and design of concrete and reinforced concrete structures, taking into account the real properties of the material.

It should be noted that in relation to concrete and reinforced concrete structures operated in aggressive environments, an additional differentiation of the factors and consequences of corrosion damage is required, which will be used in constructing calculation models of the power resistance of concrete and reinforced concrete structures.

In this regard, the creation of refined methods for the theoretical prediction of force resistance by the crack resistance of reinforced concrete structures operated in real environments is required.

The residual resource of power resistance to transverse bending at normal cross section strength in accordance with [8-15] can be calculated:

In case of colmatization corrosion damage $(m>0)$, the task involves two variants of formulation [9-20]:

First one in case

Second one in case

$$
\delta_{\mathrm{cr}}<\mathrm{X}
$$

Provided

$$
\delta_{\mathrm{cr}} \geq \mathrm{X}
$$

$$
\mathrm{X} \leq \mathrm{X}_{\mathrm{R}}
$$

The destruction of the cross section in the ultimate state in strength along the normal cross section occurs in the first case

In the second case, when

$$
\begin{array}{r}
\delta_{c r}<\mathrm{X}_{\min } \\
\mathrm{M}_{0}=\mathrm{M}_{\mathrm{cr}}^{*}
\end{array}
$$




$$
\begin{aligned}
& \delta_{c r} \geq \mathrm{X}_{\mathrm{R}} \\
& \mathrm{M}_{0}=\mathrm{M}_{\mathrm{x}}^{*}
\end{aligned}
$$

Where $\delta_{\text {cr- }}$ the maximum possible value of the depth of damage of colmatation kinetics at $\sigma=\mathrm{R}_{d}$;

$\mathrm{X}$ - the compressed section area height (the minimum of the values $\mathrm{X}_{0}, \mathrm{X}_{1}, \mathrm{X}^{*}$ is the initial height before chemical corrosion damage to the reinforced concrete element; the same in the case of corrosion damage to the reinforcement; the same in the case of simultaneous corrosion damage to concrete and reinforcement);

$\mathrm{M}_{0}$ - the force acting in the cross section from external loads;

$\mathrm{M}_{\mathrm{cr}}^{*}$ the ultimate strength resistance in strength of the section damaged by corrosion;

$\mathrm{M}_{\mathrm{x}}^{*}$ - the same with

$$
\delta_{\mathrm{cr}} \geq \mathrm{X}
$$

$\mathrm{X}_{\mathrm{R}}$ - the maximum height of the compressed zone;

$\mathrm{t}$ - the moment of strength assessment;

$t_{c r}$ the beginning of the filtration form development of chemical corrosion damage.

The destruction of bent elements along an inclined section is due to the combined action of the moments $\mathrm{M}_{0}$ and shear forces $\mathrm{Q}_{0}$.

Three cases of destruction are possible:

- shift along an inclined section;

- crushing of compressed concrete;

- the kink in an inclined section relative to the center of gravity of the compressed zone.

It should be noted that the difference in the strength estimates of reinforced concrete elements with regard to corrosion damage from traditional calculations is to take into account the loss of silt resistance of concrete, transverse and calculated reinforcement (in this case, individual empirical characteristics can be adjusted).

The strength condition in the first case is:

Where

$$
\mathrm{Q}_{0} \leq \mathrm{Q}_{\mathrm{cr}}^{*} \cong \mathrm{Q}_{\mathrm{sw}}^{*}+\mathrm{Q}_{\mathrm{b}}^{*}
$$

$\mathrm{Q}_{0}$ - lateral force from external load;

$\mathrm{Q}_{\mathrm{cr}}^{*}$ - ultimate power resistance;

$\mathrm{Q}_{\mathrm{sw}}^{*}$ - ultimate bearing capacity of transverse reinforcement of an inclined section to destruction (taking into account losses from possible corrosion damage to the reinforcement);

$\mathrm{Q}_{\mathrm{b}}^{*}$ - limit value of the power resistance in the compressed section part (taking into account losses from possible corrosion damage to concrete of the compressed section section).

It should be noted that the influence of the so-called bent reinforcement is not taken into account, and

$$
\begin{array}{r}
\mathrm{Q}_{\mathrm{sw}}^{*}=\sum \omega_{\mathrm{sw}} \cdot \mathrm{A}_{\mathrm{sw}}=\mathrm{q}_{\mathrm{sw}} \cdot \mathrm{C}^{*}=\omega_{\mathrm{sw}} \cdot \mathrm{q} \cdot \mathrm{C}(10) \\
\mathrm{Q}_{\mathrm{b}}^{*}=\frac{\mathrm{k}^{*}}{\mathrm{C}^{*}}
\end{array}
$$

Or

$$
\begin{gathered}
\mathrm{K}^{*}=1,5 \cdot\left(\mathrm{h}_{0}-\mathrm{Z}^{*}\right) \cdot\left[\left(\mathrm{h}_{0}-\mathrm{Z}^{*}\right)-\frac{1-\mathrm{K}_{1}}{3} \cdot \delta\right] \cdot \mathrm{b} \cdot \mathrm{R}_{\mathrm{bt}} \cdot \mathrm{X} \\
\mathrm{q}_{\mathrm{x}}^{*}=\frac{\omega_{\mathrm{sw}} \cdot \mathrm{A} \cdot \mathrm{R}_{\mathrm{sw}}}{\mathrm{S}}
\end{gathered}
$$

From the extreme conditions

$$
\frac{\mathrm{d}^{*} \mathrm{Q}_{\mathrm{kp}}}{\mathrm{dC}^{*}}=\mathrm{q}_{\mathrm{sw}}^{*}-\frac{\mathrm{K}^{*}}{\left(\mathrm{C}^{2 *}\right)}
$$

It turns out

$$
C^{*}=\sqrt{\frac{K^{*}}{q_{s w}^{*}}}
$$


Then the strength condition takes the form

$$
\mathrm{Q}_{0} \leq \mathrm{q}_{\mathrm{sw}}^{*} \cdot \mathrm{C}^{*}+\frac{\mathrm{K}^{*}}{\mathrm{C}^{*}}
$$

Where $\mathrm{q}_{\mathrm{sw}}^{*}$ - ultimate strength resistance to damage to the transverse reinforcement per unit length of the beam;

$\mathrm{C}^{*}$ - the projection of the inclined crack on the horizontal axis in case of damage to the compressed concrete and transverse reinforcement.

The strength condition in the second case is written:

Where

$$
\sigma_{\mathrm{mc}} \geq \mathrm{K} \cdot \mathrm{R}_{\mathrm{b}}
$$

$\sigma_{\mathrm{mc}}$ - the major compressive stress;

$$
\sigma_{\mathrm{mc}}=-0,56 \cdot \mathrm{x}-\sqrt{(0,56 \cdot \mathrm{x})^{2}+\tau^{2}}
$$

$$
\mathrm{K} \leq 1
$$

It should be noted that the second case of fracture is also probable for $\mathrm{K} \cong 1$ and a small section width $b$.

The strength condition in the third case has a similar notion as applied to the main tensile stresses, to the tensile strength of damaged concrete in tensile

Where $\sigma_{\mathrm{mt}}$ also calculated by the formula;

$$
\sigma_{\mathrm{mt}} \geq \mathrm{K} \cdot \mathrm{R}_{\mathrm{bt}, \mathrm{d}}
$$

$K \leq 1$ - the damage coefficient.

In this case, formulas (16) or (18), when solving problems, it is necessary to consider the entire range of $\sigma_{\mathrm{mc}}$ and $\sigma_{\mathrm{mt}}$ and the corresponding $\mathrm{K}$.

\section{Results}

As a result of the numerical experiment, permeating into the stretched section zone, the kinetics of chemical corrosion damage from colmatizing $(m>0)$ turns into filtration $(m=0)$ and the element is destroyed.

The height $\mathrm{X}$ is determined from the balance condition of all efforts in the projection onto the horizontal axis V [21-30]. Figure 1 shows both options.
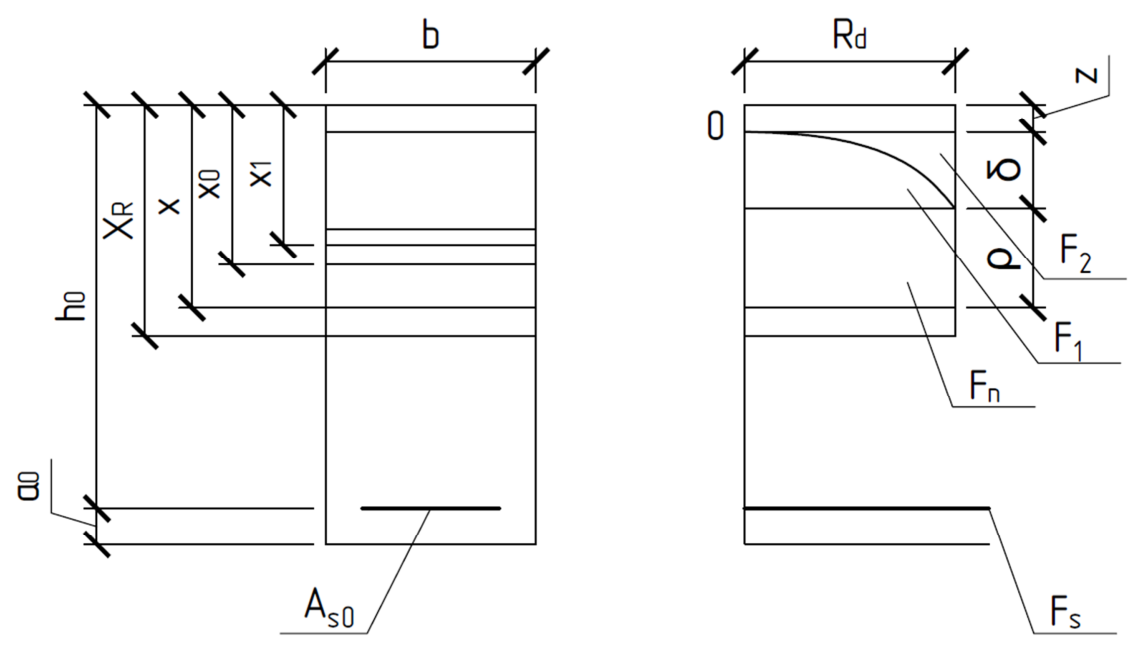
Fig.1. The force resistance diagrams in a normal section of a bent reinforced concrete element of a rectangular section with a single reinforcement

$$
\sum \mathrm{F}_{\mathrm{i}}=0
$$

That is

$$
\begin{gathered}
\mathrm{F}_{0^{-}}\left(\mathrm{F}_{\mathrm{Z}^{*}}+\mathrm{F}_{1}\right)=0 \\
\mathrm{~F}_{0}=\mathrm{b} \cdot \mathrm{X} \cdot \mathrm{R}_{\mathrm{d}} \\
\mathrm{F}_{\mathrm{z} *}=\mathrm{b} \cdot \mathrm{Z} \cdot \mathrm{R}_{\mathrm{d}} \\
\mathrm{F}_{1}=\frac{2}{3} \mathrm{~b} \cdot \delta \cdot \mathrm{R}_{d} \\
\mathrm{~F}_{1}=\frac{1}{3} \mathrm{~b} \cdot \delta \cdot \mathrm{R}_{\mathrm{d}} \\
\mathrm{F}_{\mathrm{H}}=\mathrm{b} \cdot \rho \cdot \mathrm{R}_{\mathrm{d}} \\
\mathrm{F}_{\mathrm{s}}=\omega_{\mathrm{s}} \cdot \mathrm{A}_{\mathrm{s} 0} \cdot \mathrm{R}_{\mathrm{s}}
\end{gathered}
$$

where $\mathrm{b}$ - the rectangular section width;

$\mathrm{A}_{\mathrm{s} 0}$ - initial area of stretched reinforcement;

$\mathrm{R}_{\mathrm{s}}$ - design strength of tensile reinforcement;

Where

$$
\begin{gathered}
\mathrm{X}=\mathrm{X}_{1}+\mathrm{Z}^{*}+\frac{\delta}{3} \\
\mathrm{X}_{0}=\frac{\mathrm{A}_{\mathrm{s} 0} \cdot \mathrm{R}_{\mathrm{s}}}{\mathrm{b} \cdot \mathrm{R}_{\mathrm{d}}} \\
\mathrm{X}_{1}=\omega_{1} \cdot \mathrm{X}_{0}=\frac{\mathrm{A}_{\mathrm{s} 0} \cdot \mathrm{R}_{\mathrm{s}} \cdot \omega_{\mathrm{s}}}{\mathrm{b} \cdot \mathrm{R}_{\mathrm{d}}}
\end{gathered}
$$

Moreover, according to expressions (22) - (24), it is calculated

$$
\begin{gathered}
\mathrm{X}_{0}-\text { in case } Z^{*}=0 ; \delta=0 ; \omega_{\mathrm{s}}=1 ; \\
\mathrm{X}_{1} \text { - in case } Z^{*}=0 ; \delta=0 ; \omega_{\mathrm{s}}<1 ; \\
\mathrm{X} \text { - in case } \mathrm{Z}^{*}>0 ; \delta>0 ; \omega_{\mathrm{s}}<1
\end{gathered}
$$

For the first case, the desired residual resource $\mathrm{M}_{\mathrm{cr}}^{*}$ is determined by calculating the moments relative to the gravity center of the tensile reinforcement

where $\mathrm{r}_{\mathrm{s} 1}-$ moment arm for $\mathrm{F}_{1}$;

$$
\mathrm{M}_{\mathrm{cr}}^{*}=\mathrm{F}_{1} \cdot \mathrm{r}_{\mathrm{s} 1}+\mathrm{F}_{\mathrm{H}} \cdot \mathrm{r}_{\mathrm{sH}}
$$

$\mathrm{r}_{\mathrm{sH}}$ - the same one for $\mathrm{F}_{\mathrm{H}}$, measured from the gravity center of the tensile reinforcement $A_{s}$ to the gravity centers of the diagrams $F_{1}$ and $F_{H}$. Moreover

$$
\mathrm{r}_{\mathrm{s} 1}=\mathrm{h}_{0}-\left(\mathrm{z}^{*}+\mathrm{r}_{\mathrm{V} 1}\right)
$$

(Countdown for $r_{\mathrm{V} 1}$ is carried out to the axis $\mathrm{V}$ ),

Provided

$$
\mathrm{r}_{\mathrm{V} 1}=\frac{\int_{0}^{\delta} \mathrm{kZdZ}}{\int_{0}^{\delta} \mathrm{kdZ}}=\frac{5 \cdot \delta}{8}
$$




\section{Discussion}

In particular, it has been experimentally established that the structure of concrete, its density and permeability and, therefore, corrosion permeability are directly related to the level of acting stresses. Meanwhile, modern methods for assessing the fracture toughness resource, taking into account the influence of corrosion damage, are still being developed, and in the available publications there are no proposals for taking into account some important factors; for example, the factor influencing the level of stress state on corrosion damage and crack resistance of concrete.

Since the reinforced concrete structures intended for the simultaneous perception of power and environmental influences, which can cause the loss of their functional purpose the protective potential of the structures themselves, occupy a critical place among the above structures, insofar as the occurrence of risk situations is the beginning of the occurrence of risk situations, the formation of cracks in the concrete of the stretched part sections.

In this regard, the problem of providing for a given period of preservation of crack resistance has the problem of predicting the moment of the cracks occurrence in the stretched zone of reinforced concrete structures with the maximum number and strength of power factors and corrosion origin. Such a statement raises the question how to increase the fracture toughness resource, the loss of this resource over time during the operation of structures, and the assessment of the duration of the effectiveness of structural reinforcement.

It should be noted that the difference in the strength estimates of reinforced concrete elements with regard to corrosion damage from traditional calculations is to take into account the loss of silt resistance of concrete, transverse and calculated reinforcement (in this case, individual empirical characteristics can be adjusted).

That is

$$
\mathrm{r}_{\mathrm{s} 1}=\mathrm{h}_{0}-\left(\mathrm{z}^{*}+\frac{5 \cdot \delta}{8}\right)
$$

and

$$
\mathrm{r}_{\mathrm{sH}}=\mathrm{h}_{0}-\left(\mathrm{z}^{*}+\delta+\frac{\rho}{2}\right)
$$

At

That is

$$
\rho=\mathrm{X}-\left(\mathrm{Z}^{*}+\delta\right)
$$

Or in terms of expression

$$
\mathrm{r}_{\mathrm{sH}}=\mathrm{h}_{0}-\frac{1}{2} \cdot\left(\mathrm{X}+\mathrm{Z}^{*}+\delta\right)
$$

$$
\mathrm{r}_{\mathrm{sH}}=\mathrm{h}_{0}-\frac{1}{2} \cdot\left(\mathrm{X}_{1}+2 \cdot \mathrm{Z}^{*}+\delta \cdot \frac{4}{3}\right)
$$

For the second case (6) - (7), in which $\mathrm{M}$ is also determined by calculating the moments relative to the center of the tensile reinforcement gravity

$$
\mathrm{M}_{\mathrm{cr}}^{*}=\mathrm{F}_{1} \cdot \mathrm{r}_{\mathrm{s} 1}+\mathrm{F}_{\mathrm{H}} \cdot \mathrm{r}_{\mathrm{sH}}
$$

In the calculation, formulas (20) - (29) are also used with replacement of $\delta$ by $\left(\mathrm{X}-\mathrm{Z}^{*}\right)$, where from

$$
\begin{aligned}
\mathrm{X} & =\mathrm{Z}^{*}+\mathrm{X}_{1} \cdot \frac{3}{2} \\
\mathrm{r}_{\mathrm{s} 1} & =\mathrm{h}_{0}-\mathrm{z}^{*}-\frac{15 \cdot \mathrm{X}_{1}}{16} \\
\mathrm{r}_{\mathrm{sH}} & =\mathrm{h}_{0}-\frac{2}{3} \cdot \mathrm{X}_{1}-\mathrm{Z}^{*}
\end{aligned}
$$




\section{Conclusions}

A complex calculation method is considered in this article that allows to quantitatively assessing the state and resources of crack resistance of reinforced concrete structures damaged by corrosion, to calculate the necessary levels of compression and loss of tension, as well as the exposure to preserve crack resistance in time at specific loading levels and intensities of corrosion effects. The developed complex calculation method can be presented as part of the solution to the problem of preventing and eliminating emergency situations.

The residual resource of power resistance to transverse bending at normal cross section strength in accordance with [8-15] can be calculated in case of colmatization corrosion damage $(\mathrm{m}>0)$, the task involves two variants of formulation: first one in case of $\delta_{\mathrm{cr}}<\mathrm{X}$, second one in case of $\delta_{\mathrm{cr}} \geq \mathrm{X}$.

The article considers a complex calculation method that allows you to quantitatively assess the condition and residual resources of force resistance to transverse bending by the strength of inclined sections damaged by corrosion, calculate the necessary levels of compression and loss of tension, as well as the exposure to preserve crack resistance over time at specific loading levels and intensities of corrosion effects [31-36].

\section{References}

1. V. Rimshin, R. Aralov E3S Web of Conferences, 110, № 01011. (2019)

2. E. Kuzina, V. Rimshin E3S Web of Conferences, 97, № 04007. (2019)

3. E. Kuzina, V. Rimshin Advances in Intelligent Systems and Computing, 983, pp. 911919. (2019)

4. A. Varlamov, V. Rimshin, S. Tverskoi E3S Web of Conferences, 91, 02046. (2019)

5. V. Rimshin, B. Labudin, et al., Advances in Intelligent Systems and Computing, 983, pp. 867-876. (2019)

6. E. Kuzina, V. Rimshin, V. Kurbatov, IOP Conference Series: Materials Science and Engineering, 463 (4), 042009. (2018)

7. N. Karpenko, V. Eryshev, V. Rimshin, IOP Conference Series: Materials Science and Engineering, 463 (3), 032024. (2018)

8. A. Varlamov, V. Rimshin, S. Tverskoi IOP Conference Series: Materials Science and Engineering, 463 (2), 022029. (2018)

9. A. Krishan, V. Rimshin, M. Astafeva, IOP Conference Series: Materials Science and Engineering, 463 (2), 022063. (2018)

10. A. Varlamov, V. Rimshin, S. Tverskoi IOP Conference Series: Materials Science and Engineering, 463 (2), 022028. (2018)

11. A. Krishan, V. Rimshin, E. Troshkina, IOP Conference Series: Materials Science and Engineering, 463 (2), 022062. (2018)

12. A. Krishan, M. Narkevich et al., IOP Conference Series: Materials Science and Engineering, 456 (1), 012049. (2018)

13. V. Telichenko, V. Rimshin, E. Kuzina, MATEC Web of Conferences, 251, 04061. (2018)

14. V. Telichenko, V. Rimshin et al., (2018) MATEC Web of Conferences, 196, 02025. (2018) 
15. A. Varlamov, V. Rimshin, S. Tverskoi IOP Conference Series: Earth and Environmental Science, 177 (1), 012040. (2018)

16. V. Rimshin, B. Labudin et al., ARPN Journal of Engineering and Applied Sciences, 13 (11), pp. 3851-3856. (2018)

17. V. Rimshin, A. Varlamov, Izvestiya Vysshikh Uchebnykh Zavedenii, Seriya Teknologiya Tekstil'noi Promyshlennosti, 3, pp. 63-68. (2018)

18. V. Rimshin, A. Pudova, L. Shubin Izvestiya Vysshikh Uchebnykh Zavedenii, Seriya Teknologiya Tekstil'noi Promyshlennosti, 3, pp. 287-293. (2018)

19. A. Varlamov, V. Rimshin, S. Tverskoi IFAC-PapersOnLine, 51 (30), pp. 808-811. (2018)

20. E. Kuzina, V. Rimshin, Advances in Intelligent Systems and Computing, 692, pp. 410416. (2018)

21. E. Kuzina, A. Cherkas, V. Rimshin, IOP Conference Series: Materials Science and Engineering, 365 (3), 032053. (2018)

22. A. Cherkas, V. Rimshin, MATEC Web of Conferences, 117, 00027. (2017)

23. V. Telichenko, V. Rimshin et al., Journal of Industrial Pollution Control, 33 (1), pp. 1034-1041. (2017)

24. A. Krishan, V. Rimshin et al., Izvestiya Vysshikh Uchebnykh Zavedenii, Seriya Teknologiya Tekstil'noi Promyshlennosti, 370 (4), pp. 220-225. (2017)

25. A. Krishan, V. Rimshin et al., Izvestiya Vysshikh Uchebnykh Zavedenii, Seriya Teknologiya Tekstil'noi Promyshlennosti, (2), pp. 227-232. (2017)

26. I. Shubin, Y. Zaitsev et al., Engineering Solid Mechanics, 5 (2), pp. 139-144. (2017)

27. S. Korotaev, V. Kalashnikov et al., Ecology, Environment and Conservation, 22 (3), pp. 1159-1164. (2016)

28. A. Krishan, E. Troshkina, Research Journal of Pharmaceutical, Biological and Chemical Sciences, 7 (3), pp. 2518-2529. (2016)

29. V. Erofeev, E. Zavalishin et al., (2016) Research Journal of Pharmaceutical, Biological and Chemical Sciences, 7 (3), pp. 2506-2517. (2016)

30. Y. Bazhenov, V. Erofeev et al., Engineering Solid Mechanics, 4 (4), pp. 219-225. (2016)

31. V. Erofeev, V. Kalashnikov et al., Solid State Phenomena, 871, pp. 28-32. (2016)

32. A. Krishan, V. Rimshin et al., Procedia Engineering, 117 (1), pp. 211-217. (2015)

33. V. Antoshkin, V. Travush et al., Modern Applied Science, 9 (3), pp. 46-50. (2015)

34. V. Erofeev, A. Bogatov et al., Biosciences Biotechnology Research Asia, 12 (1), pp. 661-669. (2015)

35. V. Bondarenko, A. Kurzanov, V. Rimshin, Vestnik Rossijkoj Akademii Nauk, 70 (11), pp. 1005-1009. (2000)

36. V. Rimshin, E. Larionov et al., Life Science Journal, 11 (11), pp. 278-280. (2014) 